\title{
Design of Ultra-Wideband MIMO Antenna for Breast Tumor Detection
}

\author{
Liting Wang ${ }^{1}$ and Bin Huang ${ }^{2}$ \\ ${ }^{1}$ School of Biomedical Engineering, Capital Medical University, No. 10 Xitoutiao, You An Men, Beijing 100069, China \\ ${ }^{2}$ Guilin Airforce Academy, No. 90 Kaifeng Road, Guilin 541003, China
}

Correspondence should be addressed to Liting Wang, wanglt@ccmu.edu.cn

Received 21 July 2011; Accepted 24 August 2011

Academic Editor: Yuan Yao

Copyright (C) 2012 L. Wang and B. Huang. This is an open access article distributed under the Creative Commons Attribution License, which permits unrestricted use, distribution, and reproduction in any medium, provided the original work is properly cited.

A MIMO antenna composed by microstrip line-fed circular slot antenna is proposed. This antenna is used in ultra-wideband microwave imaging systems aimed for early breast cancer detection. The antenna is designed to operate across the ultra-wideband frequency band in the air. The mutual coupling between the antenna elements has been investigated to be low enough for MIMO medical imaging applications. Both the simulation and measurement results are shown to illustrate the performances of the proposed antenna.

\section{Introduction}

Breast cancer is one of the most common types of cancer and a major cause of death among women. However, a high percentage of the cases can be cured if they are detected in time. An important tool for detection is the mammogram, which exploits the differences between the scattering cross-section of normal and malignant tissues to X-rays. But this technique presents important limitations [1]. Recently, an alternative approach is to use microwave imaging, which has the potential advantages of low cost, improved safety, and greater availability $[2,3]$. The working principle of microwave imaging techniques is based on the dielectric contrast between the malignant tumor tissues and the healthy ones [4]. In these techniques the tumor is identified from the processing of the scattered signals collected at the antennas. Several approaches can be found in the literatures. However techniques based on ultra-wideband signals have recently woken up a great deal of interest [5-7]. MIMO technique is also applied to this application [8]. In [9], an electrically switched array transmits and receives an ultra-wideband signal. Measurements are time aligned to estimate the return in a particular volumetric pixel. In [10], ultra-wideband MIMO concepts applied to tumor detection are explicitly addressed.
In this paper a novel ultra-wideband MIMO antenna is designed with this goal in mind. It can provide ultra-wideband characteristic, covering $2.3 \mathrm{GHz}-12.2 \mathrm{GHz}$. This ultrawideband characteristic is obtained by loading a rectangular patch to circular slot antenna. Two elements of such antennas are used for MIMO applications. The proposed structure obtains low mutual coupling and envelope correlation due to the orthogonal polarization.

\section{Antenna Structure and Mechanism}

As we know, wide slot antennas have received more attention due to their ultra-wideband characteristic. They are very popular for volume-limited and wideband applications. The structure of the proposed UWB MIMO antenna is shown in Figure 1. This antenna is printed on a FR-4 substrate with relative permittivity 4.4 and thickness of $1 \mathrm{~mm}$. The two identical antenna elements have the same structure and dimensions. The antenna has two layers, the top layer and the bottom layer. On the bottom layer there are the grounds with length $L_{s}$ and width $W_{s}$. There are the circular slots in the bottom ground with radius $R_{c}$. And in the circular slots there are the rectangular patches with length of $L_{p}$ and width $W_{p}$. On the top layer is the microstrip line with circular patch. 


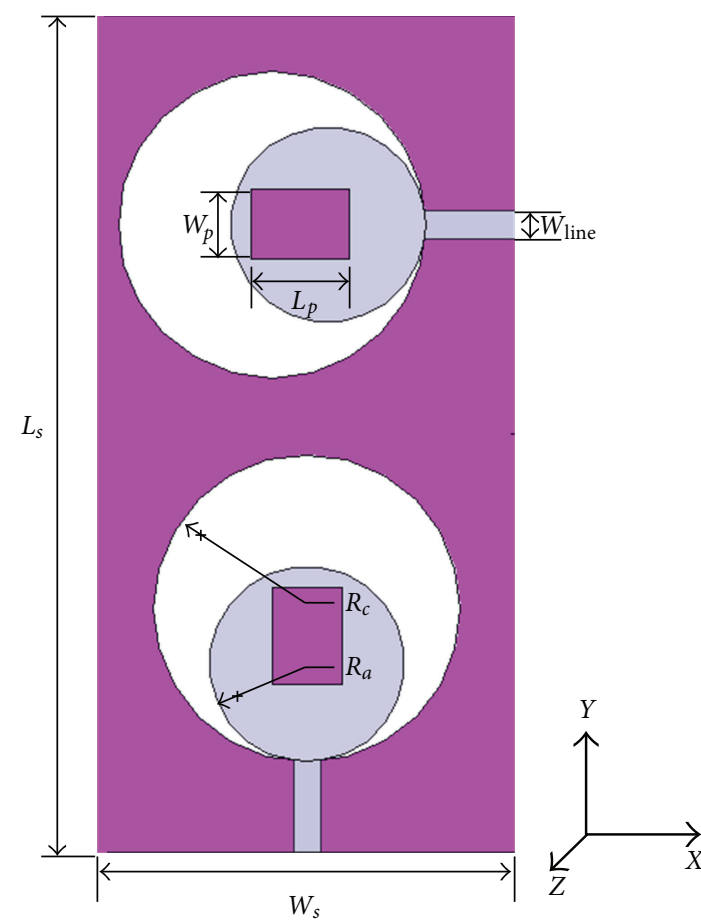

Figure 1: The geometry of the proposed antenna.

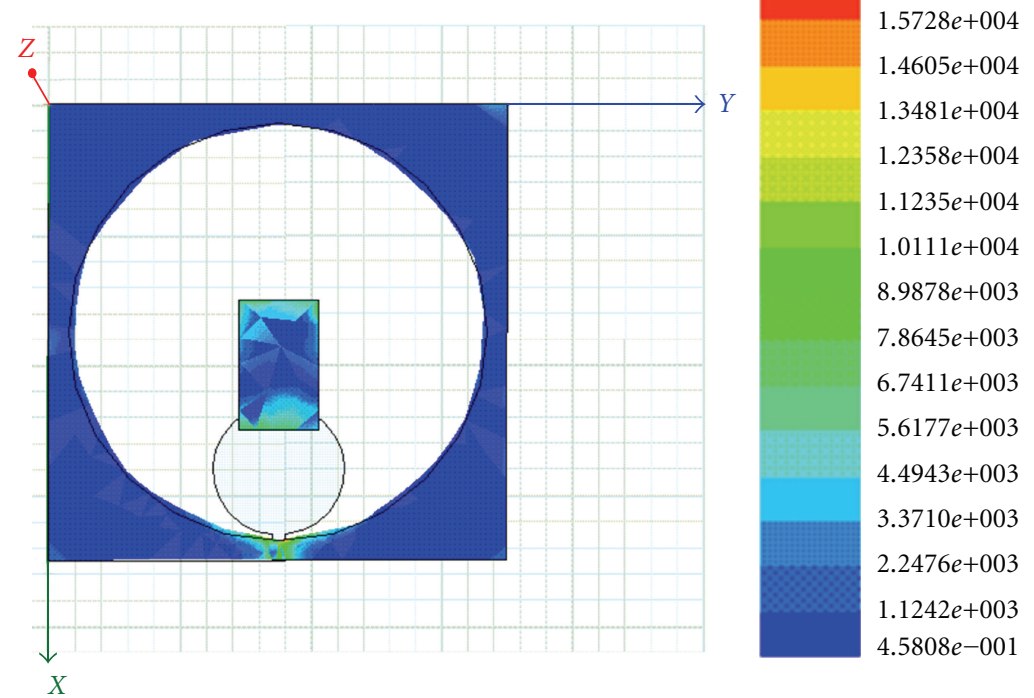

$E$ field $(\mathrm{V} / \mathrm{m})$

$1.8917 e+004$

$1.6851 e+004$

$1.5728 e+004$

$1.4605 e+004$

$1.3481 e+004$

$1.2358 e+004$

$1.1235 e+004$

$1.0111 e+004$

$8.9878 e+003$

$7.8645 e+003$

$6.7411 e+003$

$5.6177 e+003$

$4.4943 e+003$

$10 e+003$

$.2476 e+003$

$1.1242 e+003$

Figure 2: Current distribution at $4 \mathrm{GHz}$.

The fed line with width $W_{\text {line }}$ to match $50 \Omega$ and the radius of the circular patch is $R_{a}$. The two identical antenna elements are connected with no spacing between them. The detailed antenna dimensions are listed in Table 1.

According to Babinet's theory, the slot antenna can be solved through analyzing its complementary antenna. So the circular slot in this paper can be seen as equivalent to a disk monopole antenna which is already studied [11, 12]. The circular slot antenna has wideband characteristic covering from 6 to $10 \mathrm{GHz}$. And the rectangular patch in the slot greatly impacts the impedance bandwidth characteristics of the antenna. Figure 2 shows the current distributions on the circular slot antenna with rectangular patch at $4 \mathrm{GHz}$. It can be seen that the rectangular patch resonates at $4 \mathrm{GHz}$ and 


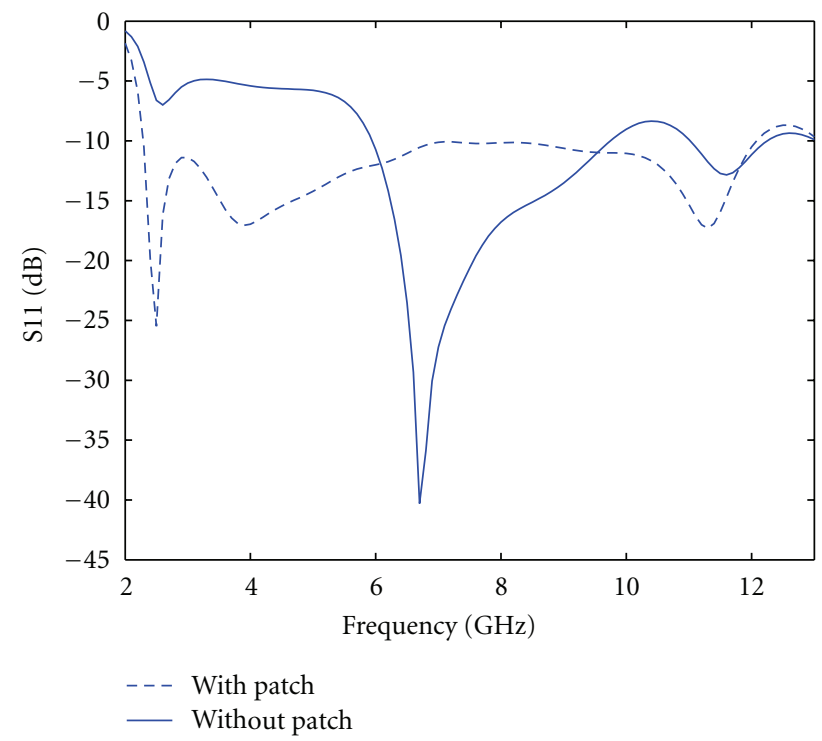

FIGURE 3: Return loss of the slot antenna with and without the rectangular patch.

TABle 1: Antenna dimensions.

\begin{tabular}{llllllll}
\hline Dimension & $L_{s}$ & $W_{s}$ & $L_{p}$ & $W_{p}$ & $R_{c}$ & $R_{a}$ \\
\hline Size $(\mathrm{mm})$ & 70 & 35 & 10 & 6 & 16 & 5 \\
\hline
\end{tabular}

widens the frequency band. Figure 3 shows the return loss of the antenna with and without rectangular patch. Thus the proposed antenna has ultra-wideband characteristic.

Compared with the traditional antenna parameters, such as gain, radiation pattern, and reflection coefficients, new parameters and aspects have to be included in the design for MIMO systems. Mutual coupling between antenna elements is a key factor to achieve high antenna performance in the MIMO antenna configuration. For a low mutual coupling, antennas must be far away from each other. But the space for the internal antenna is not enough to obtain low correlation and mutual coupling. In this paper we present a structure for the MIMO antenna elements, in which the identical two antenna elements are orthogonally placed. Then the two antenna elements have orthogonal polarization which can reduce the mutual coupling between the two antennas. Figure 4 shows the simulated $3 \mathrm{D}$ radiation patterns of the two antenna elements. It can be seen that the two antenna elements have orthogonal polarizations.

\section{Simulation and Measurement Results}

Both the simulation and measurement are carried out to verify the above analysis. The proposed structure is simulated in HFSS and measured in an anechoic chamber. The fabricated proposed UWB MIMO antenna is shown in Figure 5. The detailed dimensions can be found in Table 1. Figure 6 shows the simulated and measured return loss, which agree well. The measured $10 \mathrm{~dB}$ return loss bandwidths are from 2.3 GHz to $12.2 \mathrm{GHz}$, which covers an ultra-wideband. The mutual coupling between the two ports is less than $-15 \mathrm{~dB}$ across the common bandwidth, as shown in Figure 7.

Figures 8 and 9 show the radiation patterns of the antenna 1 and the antenna 2 at $3 \mathrm{GHz}, 6 \mathrm{GHz}$, and $8 \mathrm{GHz}$ at E-plane and $\mathrm{H}$-plane, respectively. The antenna 1 has bidirectional vertically polarized patterns, and the antenna 2 generates horizontally polarized radiations. Thus the proposed antenna is more attractive for ultra-wideband MIMO application for breast tumor detection.

\section{Parameter Study}

For the purpose of optimized performance, parametric studies of the dimensions of the antenna structure are carried out. First, we analyze the length of the rectangular patch in the slot. As shown in Figure 10, when the length equals $8 \mathrm{~mm}$, the lower frequency band is bad. And when the length is $10 \mathrm{~mm}$, the impedance matching is good over the whole band. When the length is $12 \mathrm{~mm}$, even though its lower frequency band is better than $10 \mathrm{~mm}$, the middle frequency band is worse. Thus the $10 \mathrm{~mm}$ is the best length.

Second, we analyze the radius of the microstrip circular patch. The radius varied from $4 \mathrm{~mm}, 5 \mathrm{~mm}$, to $6 \mathrm{~mm}$ while other parameters are fixed. As shown in Figure 11, when the radius is $4 \mathrm{~mm}$, the return loss at $5 \mathrm{GHz}-6 \mathrm{GHz}$ and $9 \mathrm{GHz}-$ $11 \mathrm{GHz}$ is bad. When the radius is $5 \mathrm{~mm}$, the impedance matching is good. When the radius equals $6 \mathrm{~mm}$, the return loss gets worse. Thus, the radius is $5 \mathrm{~mm}$ in the proposed antenna.

The isolation between two polarizations will be affected by the dimension of spacing. In principle, the larger of 


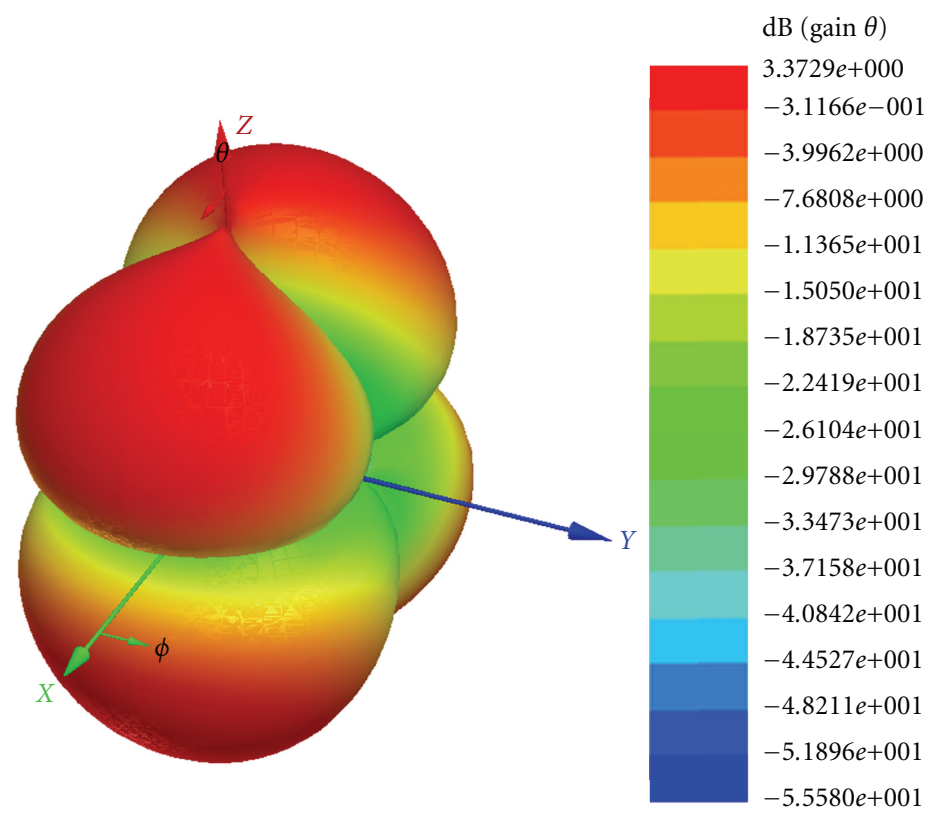

(a)
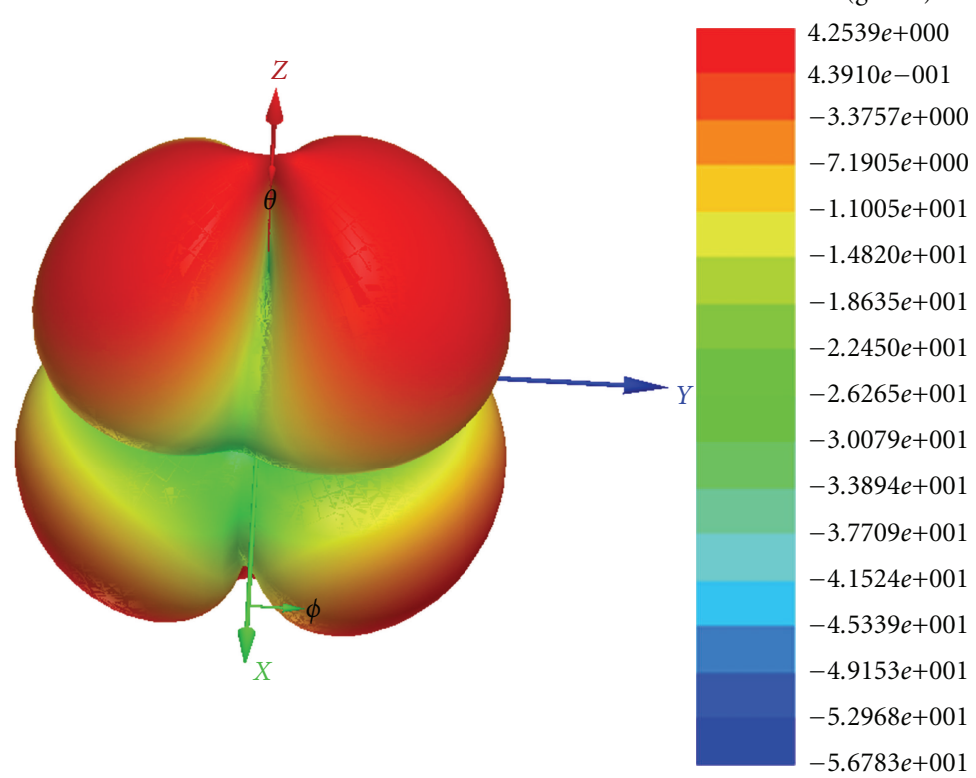

(b)

Figure 4: 3D radiation patterns of the two antenna elements.

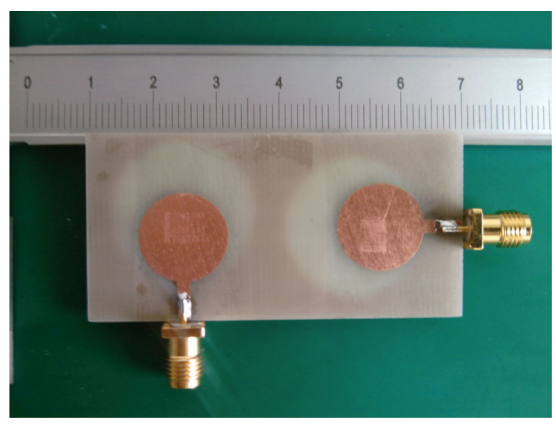

(a) top layer

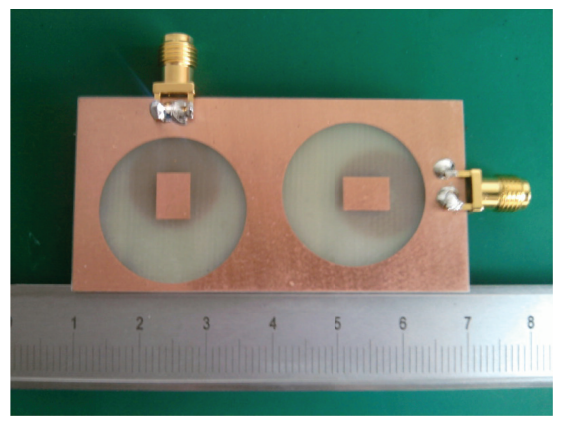

(b) bottom layer

Figure 5: Fabricated proposed antenna. 


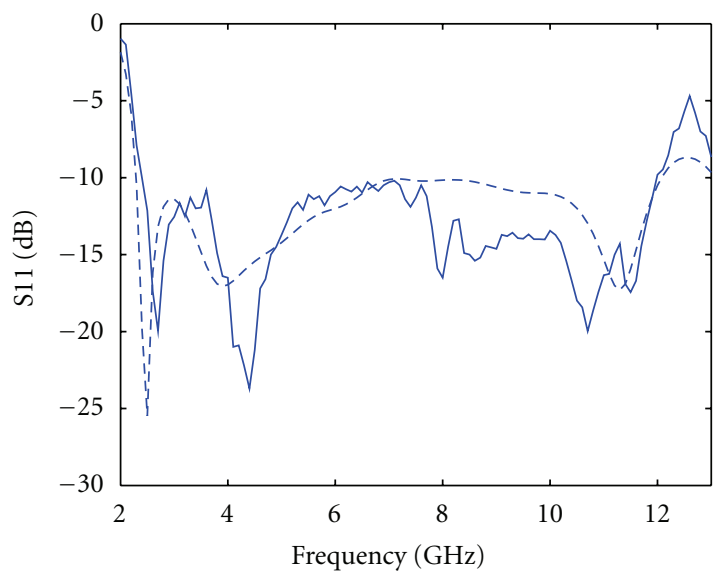

Simulated

— Measured

FIGURE 6: Simulated and measured S11.

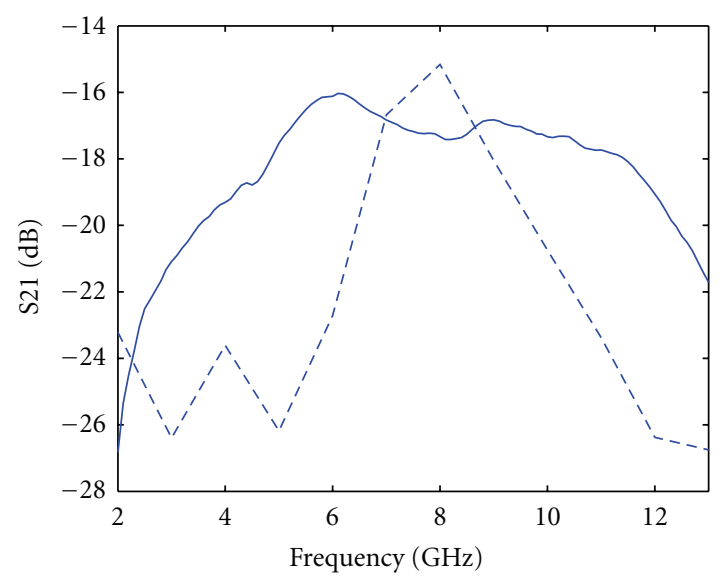

- - - Simulated

- Measured

FIGURE 7: Simulated and measured S21.
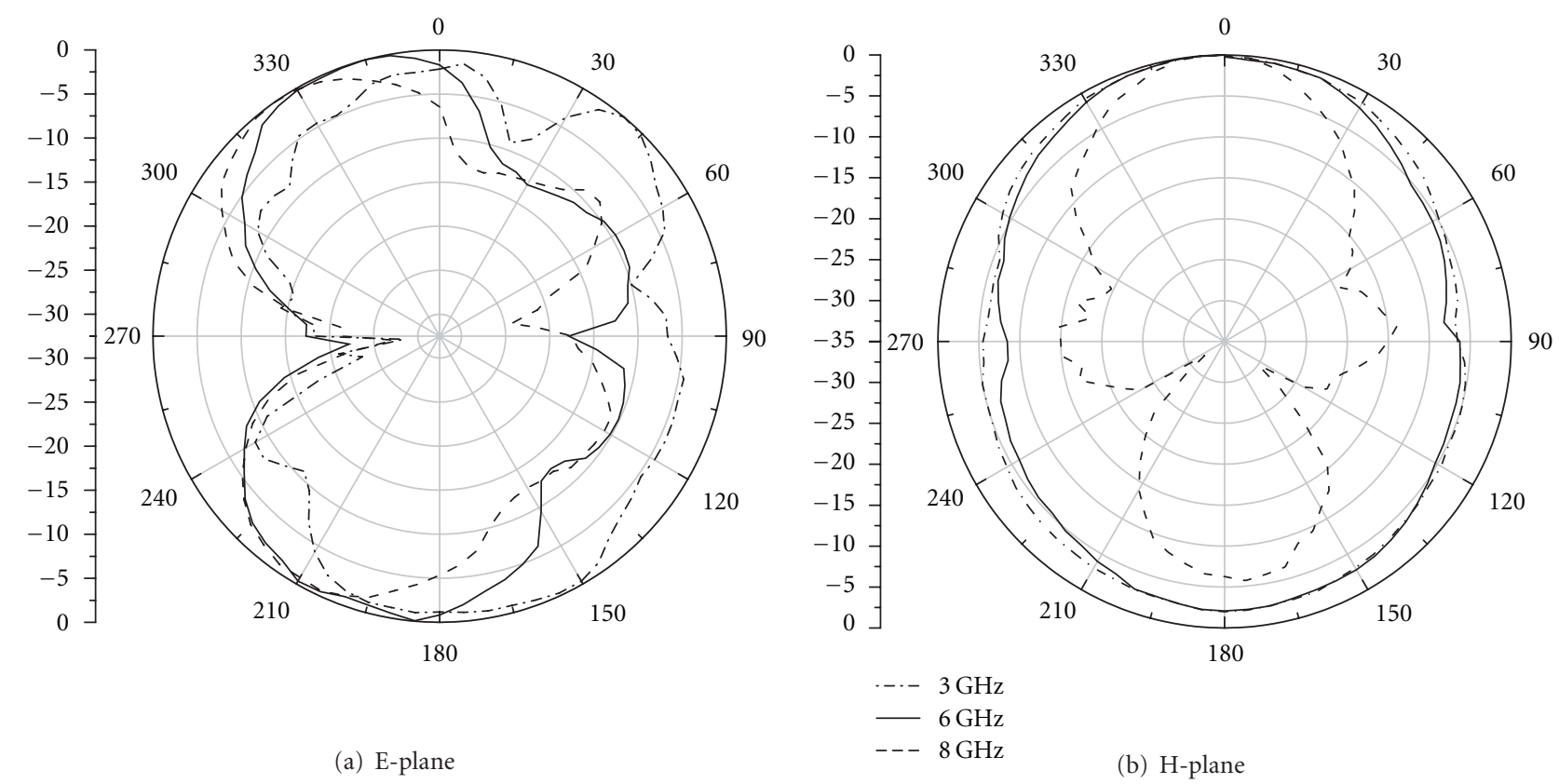

(a) E-plane

(b) H-plane

FIGURE 8: Radiation patterns of antenna 1 at $3 \mathrm{GHz}, 6 \mathrm{GHz}$ and $8 \mathrm{GHz}$. 


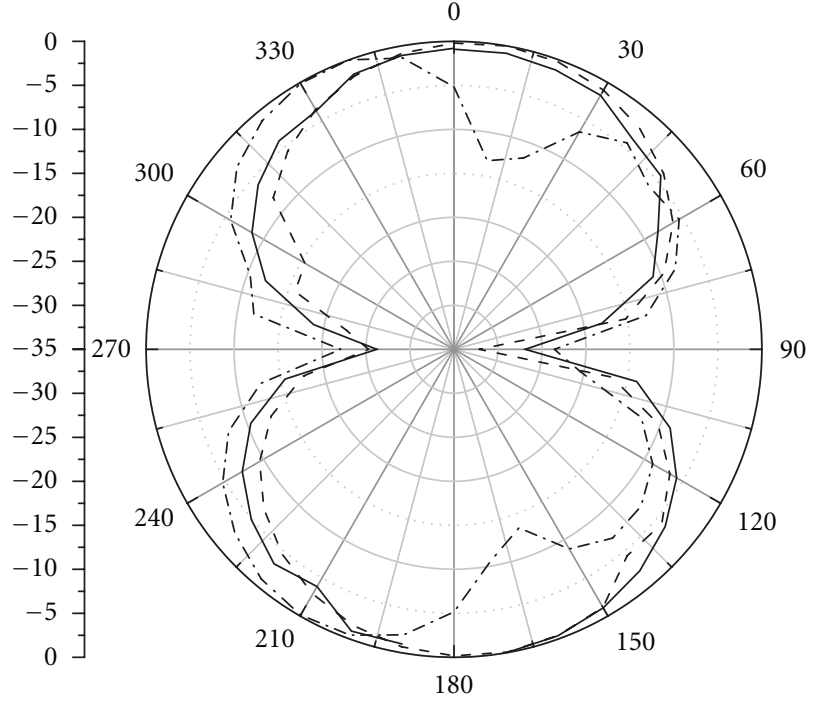

(a) E-plane

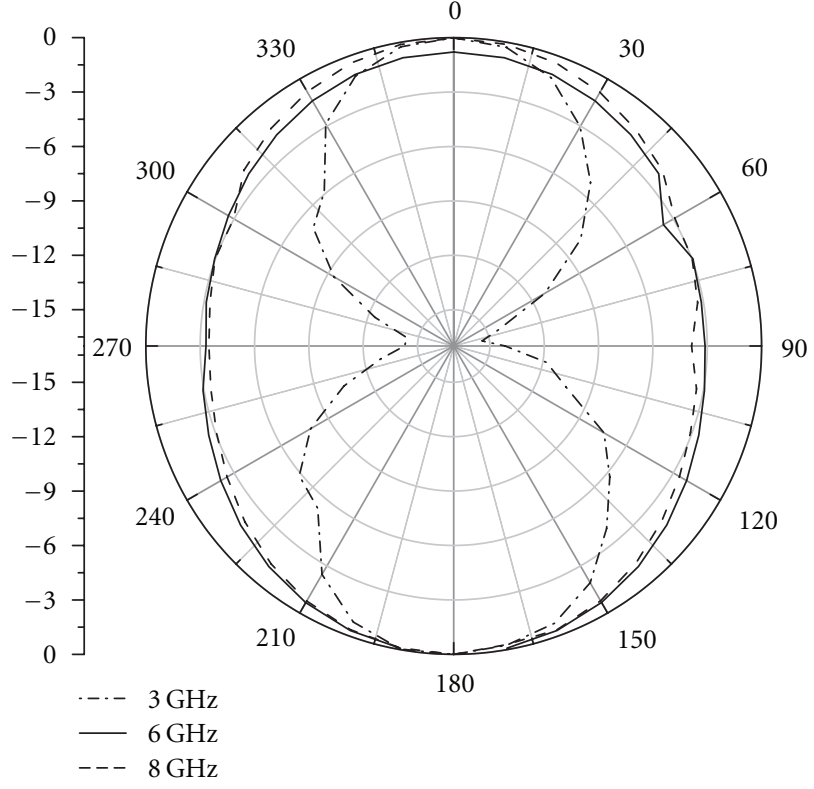

(b) H-plane

FIGURE 9: Radiation patterns of antenna 2 in $y$-z plane.

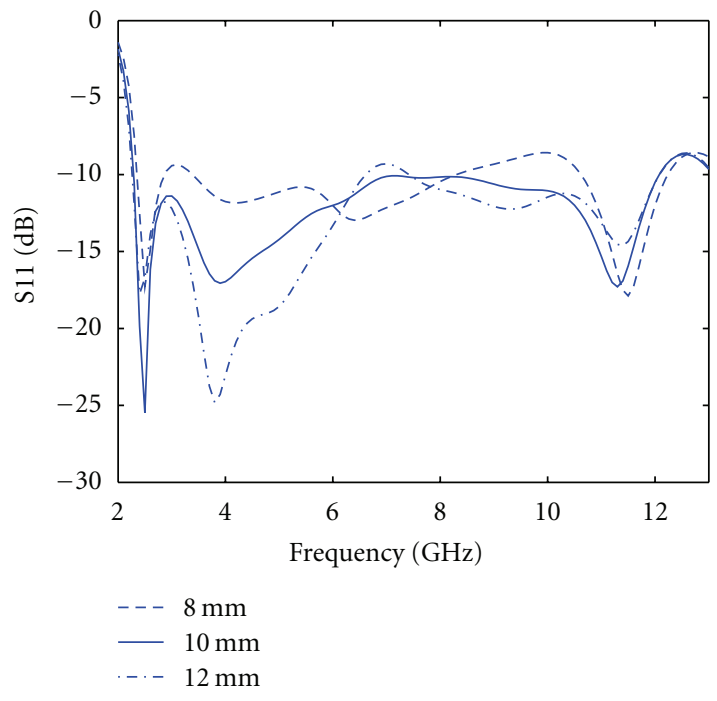

Figure 10: S11 of the antenna with different Lp.

the spacing, the lower of the mutual coupling will be obtained. In this paper the spacing of the two antenna elements is zero which means that the grounds of the two antenna elements are connected without any gap and the mutual coupling is lower than $-15 \mathrm{~dB}$ over the entire band so there is no need to increase the gap between the two antenna elements.

\section{Conclusion}

In this paper a design of ultra-wideband MIMO antenna for breast tumor detection has been proposed and implemented. Simulated and measured results showed that the antenna can

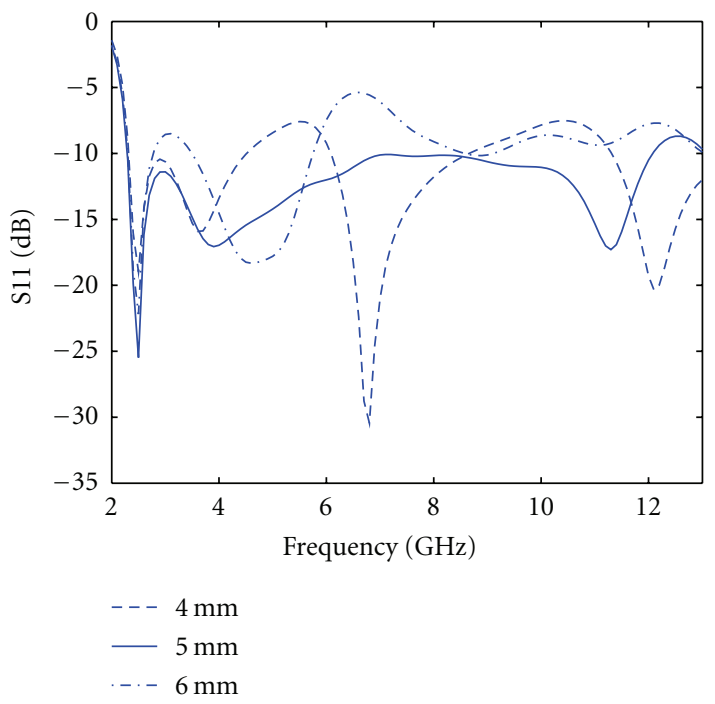

FIGURE 11: S11 of the antenna with different Ra.

cover from $2.3 \mathrm{GHz}$ to $12.2 \mathrm{GHz}$ and has high isolation. The proposed antenna will provide better performance to detect breast tumor.

\section{References}

[1] M. Klemm, I. J. Craddock, J. A. Leendertz, A. Preece, and R. Benjamin, "Radar-based breast cancer detection using a hemispherical antenna array - Experimental results," IEEE Transactions on Antennas and Propagation, vol. 57, no. 6, pp. 16921704, 2009.

[2] A. Lazaro, R. Villarino, and D. Girbau, "Design of tapered slot Vivaldi antenna for UWB breast cancer detection," Microwave 
and Optical Technology Letters, vol. 53, no. 3, pp. 639-643, 2011.

[3] Y. Xie, B. Guo, J. Li, and P. Stoica, "Novel multistatic adaptive microwave imaging methods for early breast cancer detection," Eurasip Journal on Applied Signal Processing, vol. 2006, Article ID 91961, 13 pages, 2006.

[4] M. Lazebnik, D. Popovic, L. McCartney et al., "A large-scale study of the ultrawideband microwave dielectric properties of normal, benign and malignant breast tissues obtained from cancer surgeries," Physics in Medicine and Biology, vol. 52, no. 20, pp. 6093-6115, 2007.

[5] Y. Chen, E. Gunawan, K. S. Low, S. C. Wang, Y. Kim, and C. B. Soh, "Pulse design for time reversal method as applied to ultrawideband microwave breast cancer detection: a twodimensional analysis," IEEE Transactions on Antennas and Propagation, vol. 55, no. 1, pp. 194-204, 2007.

[6] S. K. Davis, B. D. Van Veen, S. C. Hagness, and F. Kelcz, "Breast tumor characterization based on ultrawideband microwave backscatter," IEEE Transactions on Biomedical Engineering, vol. 55, no. 1, pp. 237-246, 2008.

[7] I. Hilger, C. Geyer, G. Rimkus et al., "Could we use UWB sensing for breast cancer detection?" in Proceedings of the 4th European Conference on Antennas and Propagation (EuCAP '10), pp. 1-4, April 2010.

[8] O. T. Z. Daniel, Z. Yuanjin, and L. Zhiping, "Design and experimental investigation of UWB microwave imaging via MIMO beamforming," in Proceedings of the IEEE International Conference on Ultra-Wideband (ICUWB '10), pp. 851-854, September 2010.

[9] S. K. Davis, H. Tandradinata, S. C. Hagness, and B. D. Van Veen, "Ultrawideband microwave breast cancer detection: a detection-theoretic approach using the generalized likelihood ratio test," IEEE Transactions on Biomedical Engineering, vol. 52, no. 7, pp. 1237-1250, 2005.

[10] D. W. Bliss and K. W. Forsythe, "MIMO radar medical imaging: self-interference mitigation for breast tumor detection," in Proceedings of the 40th Asilomar Conference on Signals, Systems, and Computers (ACSSC '06), pp. 1558-1562, November 2006.

[11] J. Powell and A. Chandrakasan, "Spiral slot patch antenna and circular disc monopole antenna for 3.1-10.6 GHz," IEEE Transactions on Antennas and Propagation, vol. 46, no. 2, pp. 44-49, 1998.

[12] Z. H. Song, J. R. Qi, J. H. Qiu, and T. X. Zhou, "Study of properties of the circular monopole ultra-wideband antenna," Journal of Harbin Engineering University, vol. 28, no. 1, pp. 2630, 2007. 

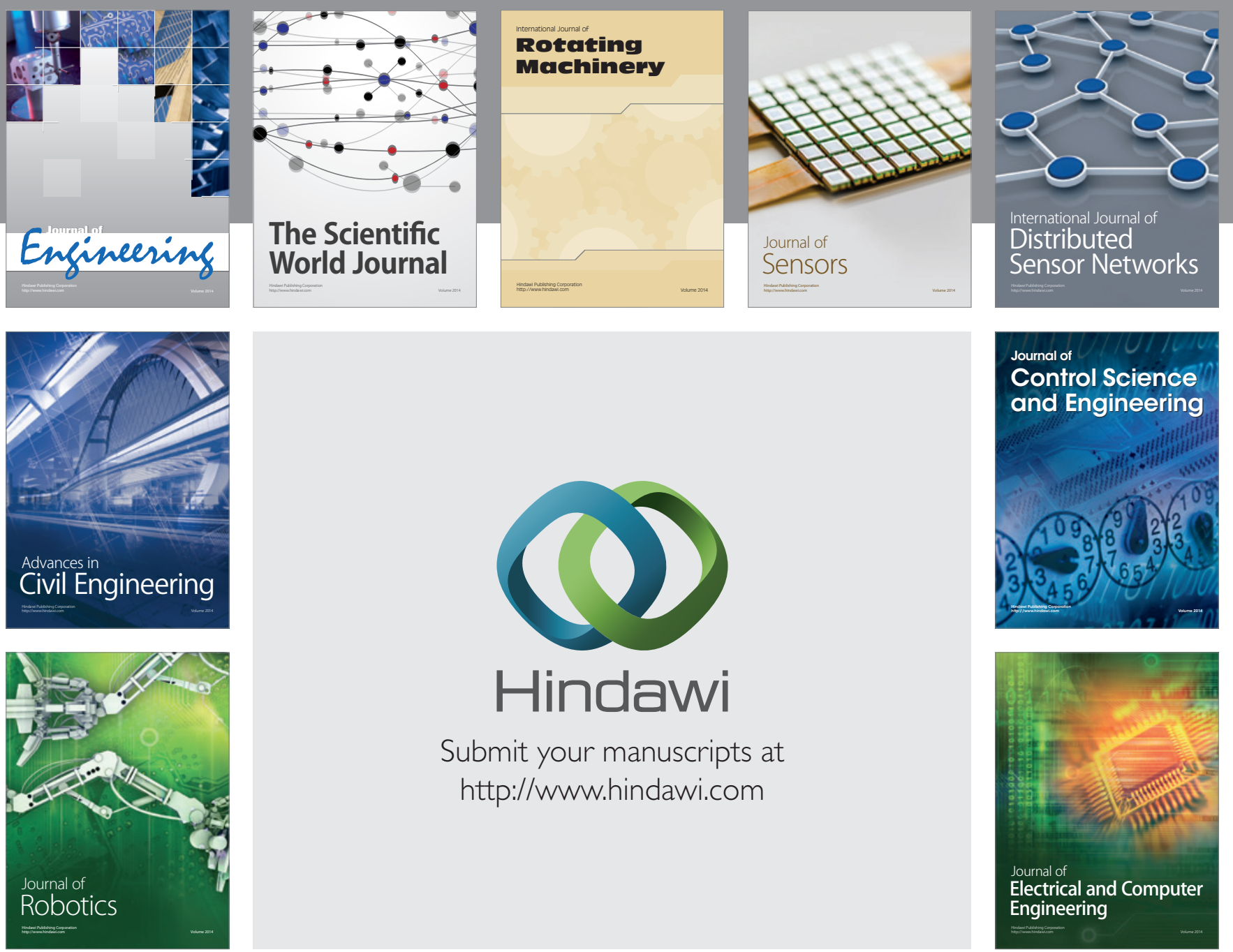

Submit your manuscripts at

http://www.hindawi.com
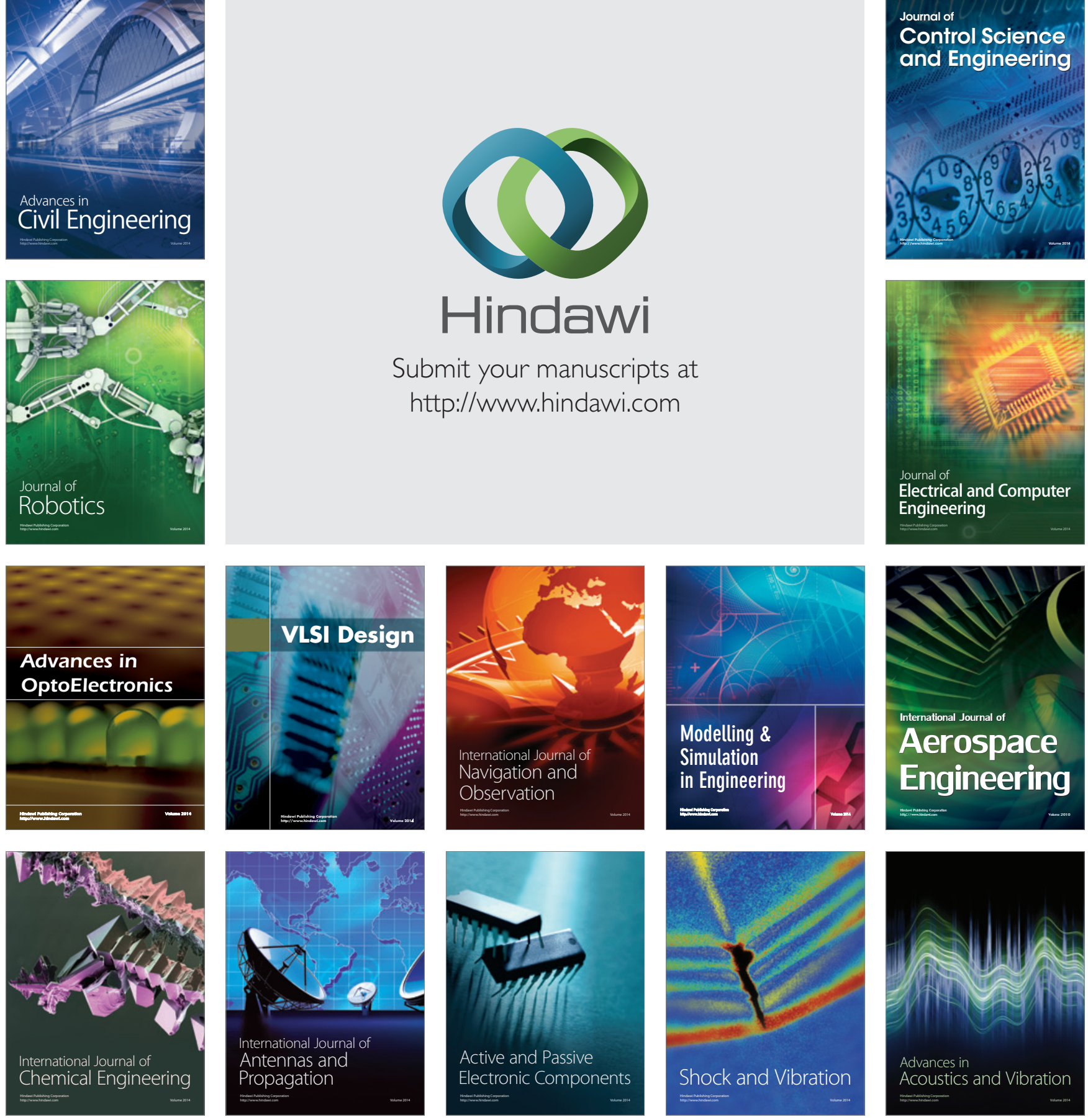